
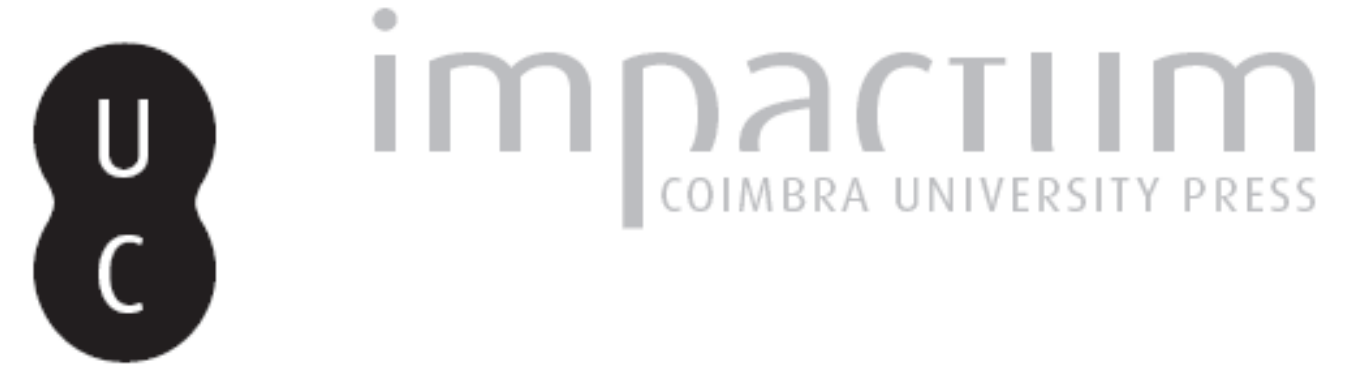

Disciplina familiar e estratégias matrimoniais da Casa de Aveiro (séculos XVli e XVII)

Autor(es): Mata, Cristóvão

Publicado por: Imprensa da Universidade de Coimbra

URL persistente:

URI:http://hdl.handle.net/10316.2/40684

DOI:

DOI:https://doi.org/10.14195/0870-4147_47_9

Accessed : $\quad$ 26-Apr-2023 15:54:03

A navegação consulta e descarregamento dos títulos inseridos nas Bibliotecas Digitais UC Digitalis, UC Pombalina e UC Impactum, pressupõem a aceitação plena e sem reservas dos Termos e Condições de Uso destas Bibliotecas Digitais, disponíveis em https://digitalis.uc.pt/pt-pt/termos.

Conforme exposto nos referidos Termos e Condições de Uso, o descarregamento de títulos de acesso restrito requer uma licença válida de autorização devendo o utilizador aceder ao(s) documento(s) a partir de um endereço de IP da instituição detentora da supramencionada licença.

Ao utilizador é apenas permitido o descarregamento para uso pessoal, pelo que o emprego do(s) título(s) descarregado(s) para outro fim, designadamente comercial, carece de autorização do respetivo autor ou editor da obra.

Na medida em que todas as obras da UC Digitalis se encontram protegidas pelo Código do Direito de Autor e Direitos Conexos e demais legislação aplicável, toda a cópia, parcial ou total, deste documento, nos casos em que é legalmente admitida, deverá conter ou fazer-se acompanhar por este aviso.

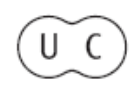




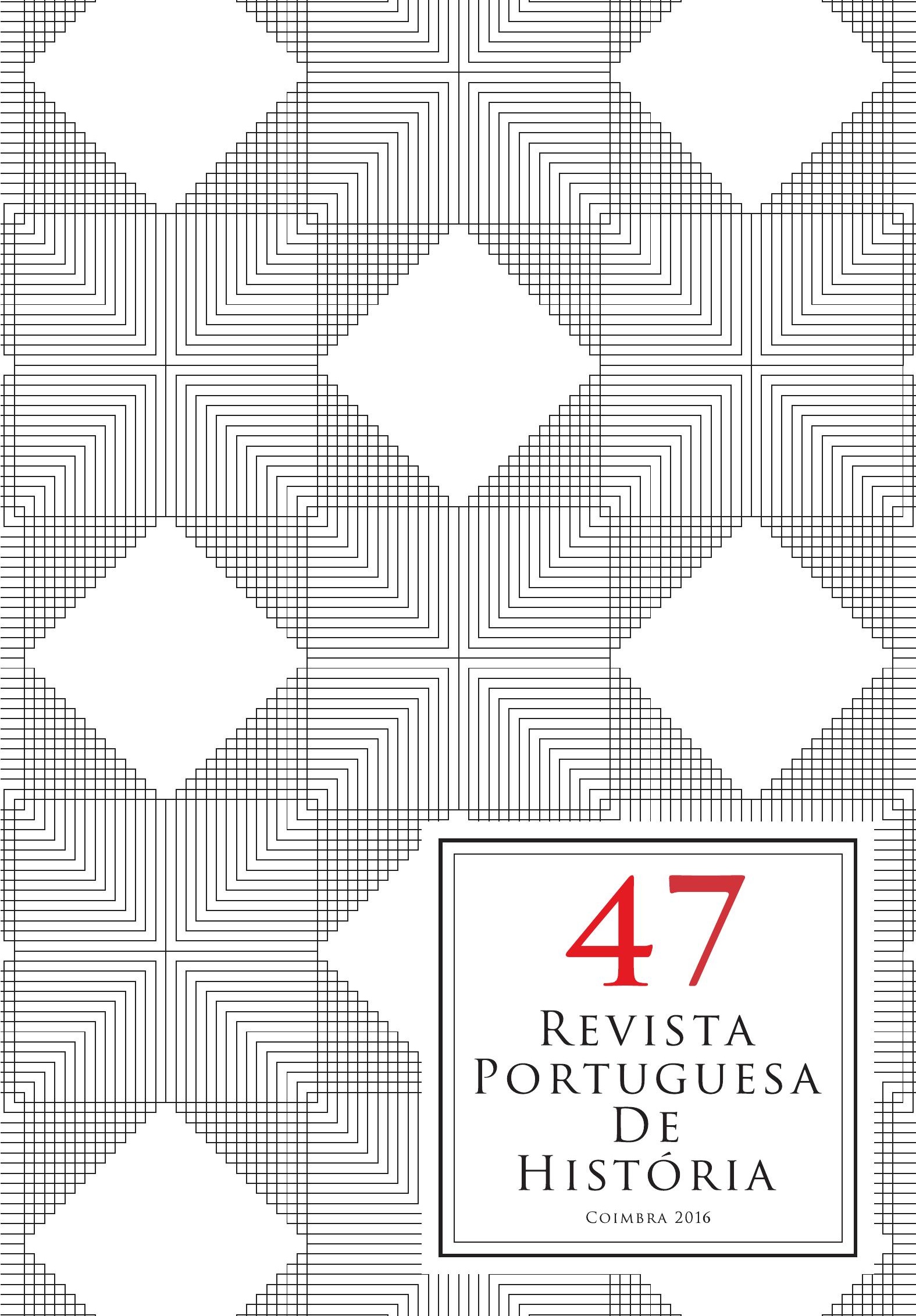




\title{
Disciplina familiar e estratégias matrimoniais da Casa de Aveiro (Séculos XVI e XVII)
}

\author{
Family discipline and matrimonial strategies: The House of Aveiro \\ in the sixteenth and seventeenth centuries
}

\author{
CRISTÓVÃo Mata \\ Doutorando do curso de $3 .^{\circ}$ ciclo Altos Estudos em História - Época Moderna \\ Faculdade de Letras da Universidade de Coimbra \\ cristovaomat@hotmail.com
}

Texto recebido em/Text submitted on: 31/01/2016

Texto aprovado em/Text approved on: 22/06/2016

Resumo:

O objetivo deste artigo consiste em verificar os índices de natalidade, de geração de filhos ilegítimos e de mortalidade infantil dos filhos dos duques de Coimbra, de Aveiro e de Torres Novas durante os séculos XVI e XVII, e em analisar os percursos de cada indivíduo que atingiu a idade adulta, comparando os valores dos que enveredaram pelo celibato e dos que contraíram matrimónio. Relativamente aos celibatários, procurar-se-á interpretar as escolhas das casas religiosas em que cada um deles se recolheu. No que concerne à amostra dos herdeiros em cujo matrimónio se investiu, serão discutidas as estratégias matrimoniais dos filhos e das filhas de seis varões da Casa de Aveiro, analisando a origem dos respetivos nubentes e os contratos matrimoniais dos primogénitos.

Palavras chave:

Aristocracia; Casa de Aveiro; Disciplina Familiar; Estratégias Matrimoniais.
Abstract:

The aim of this article is to study the Dukes of Coimbra, Aveiro and Torres Novas children birth, generation of illegitimate children and infant mortality rates during the sixteenth and seventeenth centuries and to analyze the destiny of every individual who has reached adulthood, comparing the values from the ones who have gone for celibacy and those who have married. Regarding the non-married it will be made an overview from religious houses where they have joined while from those who have married it will be discussed their matrimonial strategies, analyzing the origin of their husbands and wives and the marriage contracts of the firstborns.

Keywords:

Aristocracy; House of Aveiro; Family Discipline; Matrimonial Strategies. 
O presente artigo constitui um estudo de caso referente aos comportamentos familiares da aristocracia portuguesa da Época Moderna e pretende analisar os percursos individuais das filhas e dos filhos da Casa de Aveiro nascidos nos séculos XVI e XVII. No seu horizonte encontra-se a intenção de contribuir para o desenvolvimento de um trabalho de âmbito mais alargado sobre o regime senhorial em Portugal e os mecanismos de domínio jurisdicional exercidos pelos duques de Aveiro nos seus senhorios ${ }^{1}$. O seu objetivo imediato, porém, consiste em observar a reprodução biológica das primeiras gerações desta casa senhorial, examinando aspetos como o nascimento de filhos ilegítimos e a mortalidade infantil, e estudar a vigência de uma disciplina familiar que determinou os destinos tomados pelos filhos e filhas dos duques de Coimbra, Aveiro e Torres Novas, encaminhando-os ora para a vida celibatária, ora para matrimónios que assegurassem descendência.

Esta abordagem à nobreza portuguesa não é inédita. Em 1986, James L. Boone recorreu à informação genealógica compilada por Cristóvão Alão de Morais na sua célebre obra e estudou o investimento parental de vários estratos nobiliárquicos no decurso de um período compreendido entre 1380 e 1580 . Nesse trabalho concluiu que as probabilidades de um jovem nobre contrair matrimónio estavam relacionadas com as condições materiais da sua família. Mais concretamente, verificou que a alta nobreza investia predominantemente nos filhos do sexo masculino, enquanto as filhas dos escalões nobiliárquicos mais baixos tendiam a realizar casamentos hipergâmicos².

Os estudos de Mafalda Soares da Cunha relativos à Casa de Bragança revelam que durante os séculos XIV e XV os senhores desta casa aristocrática procuraram casar o maior número de filhos. Esta estratégia familiar pretendeu potenciar o capital social dos duques de Bragança e, em simultâneo, aumentar o património da sua casa mediante o ingresso de recursos que a celebração de matrimónios proporcionava ${ }^{3}$. No século XVI, verificou-se a redução acentuada do número total de casamentos e implementou-se uma maior seletividade na

\footnotetext{
${ }^{1}$ A Casa de Aveiro na constelação dos poderes senhoriais: estruturas de domínio e redes clientelares, projeto de doutoramento financiado pela Fundação para a Ciência e a Tecnologia, com a referência SFRH/BD/93202/2013, desenvolvido ao abrigo do curso de terceiro ciclo Altos Estudos em História - Época Moderna, da Faculdade de Letras da Universidade de Coimbra, e orientado pela Professora Doutora Margarida Sobral Neto, a quem muito encarecidamente agradecemos a revisão e as sugestões que enriqueceram este artigo.

${ }^{2}$ James L. Boone, "Parental Investment and Elite Family Structure in Preindustrial States: A Case Study of Late Medieval-Early Modern Portuguese Genealogies", American Anthropologist, New Series, 88, 4 (1986), p. 859-878.

${ }^{3}$ Mafalda Soares da Cunha, Linhagem, Parentesco e Poder. A Casa de Bragança (13841483), Lisboa, Fundação Casa de Bragança, 1990, p. 17-77.
} 
escolha dos nubentes, privilegiando-se a celebração de casamentos com filhos e filhas de Grandes de Espanha, com elementos da mesma linhagem e com membros da Casa Real ${ }^{4}$.

Os trabalhos de Nuno Gonçalo Monteiro reportam-se a uma época posterior e incidem num grupo social bastante restrito. Neles são destacadas a vigência de uma forte disciplina familiar que, até meados do século XVIII, remeteu ao celibato os secundogénitos dos Grandes de Portugal, assim como a preferência por cônjuges de estatuto social semelhante para os filhos e filhas que contraíram matrimónio 5 . A vulgarização do celibato aristocrático ocorreu no âmbito de uma estratégia de reprodução social, comum a todas as casas de Grandes, que procurou preservar o património material e simbólico da aristocracia portuguesa em função de certos constrangimentos legais. Nomeadamente do enquadramento jurídico ao qual estava sujeita a sucessão na administração de bens da Coroa e das ordens militares ${ }^{6}$, dos quais a nobreza portuguesa tanto dependia, assim como do progressivo recurso à vinculação de bens patrimoniais em morgadio ${ }^{7}$, na medida em que ambos os mecanismos condicionavam a disponibilidade dos bens materiais necessários ao investimento no casamento dos secundogénitos ${ }^{8}$.

A noção de disciplina familiar significava a subordinação dos interesses individuais aos da casa aristocrática, uma entidade que se reportava a «um conjunto coerente de bens simbólicos e materiais a cuja reprodução alargada

${ }^{4}$ Mafalda Soares da Cunha, "Estratégias Matrimoniais da Casa de Bragança e o Casamento do Duque D. João II”, Hispania, LXIV/1, 216 (2004), p. 39-62.

${ }^{5}$ Nuno Gonçalo Monteiro, "Casamento, celibato e reprodução social: a aristocracia portuguesa nos séculos XVII e XVIII”, Análise Social, 123-124 (1993), p. 921-950, O Crepúsculo dos Grandes. A Casa e o Património da Aristocracia em Portugal (1750-1832), Lisboa, Imprensa Nacional-Casa da Moeda, 2003, pp. 55-201 e "Casa, casamento e nome: fragmentos sobre relações familiares e indivíduos" in José Mattoso (dir.), História da Vida Privada em Portugal, 3, Nuno Gonçalo Monteiro (coord.), A Idade Moderna, Lisboa, Temas e Debates, 2011, p. 130-159.

${ }^{6}$ Paulo Merêa, "Génese da «Lei Mental». (Algumas Notas)» in Novos Estudos de História do Direito, Barcelos, s.n., 1937, p. 61-74.

${ }^{7}$ Maria de Lurdes Rosa, O Morgadio em Portugal (sécs. XIV-XV), Lisboa, Editorial Estampa, 1995.

${ }^{8}$ Mafalda Soares da Cunha, “A Nobreza Portuguesa no Início do Século XV: Renovação e Continuidade”, Revista Portuguesa de História, XXXI, II (1996), p. 219-252; Mafalda Soares da Cunha e Nuno Gonçalo Monteiro, "Aristocracia, Poder e Família em Portugal, Séculos XV-XVIII”, in Mafalda Soares da Cunha e Juan Hernández Franco (orgs.), Sociedade, Família e Poder na Península Ibérica. Elementos para uma História Comparativa, Lisboa, Edições Colibri, 2010, p. 47-75 e Nuno Gonçalo Monteiro e João Paulo Salvado, "La Administración de los Patrimonios de las Grandes Casas Aristocráticas en el Portugal del Antiguo Régimen", in Raúl Molina Recio (Dir.), Familia y Economía en los territorios de la Monarquía Hispánica (ss. XVI-XVIII), Badajoz, Editoral Mandalay, 2014, p. 241-264. 
estavam obrigados todos os que nela nasciam ou dela dependiam ${ }^{9}$. Muito embora a destrinça das duas categorias de bens não seja simples de realizar, a primeira reúne os títulos nobiliárquicos que distinguiam uma determinada casa, o brasão de armas que a representava, os apelidos com os quais os seus membros se identificavam ou ainda a lembrança de ter sido fundada por determinado indivíduo, enquanto a sua dimensão material se compunha da disposição de morgados ou de património livre, da posse de senhorios ou de outros bens de natureza económica ${ }^{10}$.

Sobre a noção de casa, importa acrescentar que se tratava de um conceito polissémico, conforme demonstra o verbete que Rafael Bluteau dedicou ao termo naquele que é considerado o dicionário de língua portuguesa mais antigo. O vocábulo surge em sinonímia com o conceito de casa de habitação e de tudo o que esta pode conter, da família que abriga aos seus móveis e alfaias. Em determinado parágrafo, o autor considera-a equivalente a «familia. Geração. [...] Moveis. Criados» ${ }^{11}$. Na Época Moderna, todavia, a conceção de família não se reportava unicamente a um grupo cujos membros se encontravam mutuamente ligados por laços de parentesco biológico. Englobava também todos aqueles que habitavam um determinado agregado, como os criados que o lexicógrafo teatino mencionava e sobre quem a autoridade do senhor da casa se exercia ${ }^{12}$.

Foi neste sentido que a casa senhorial constituiu o objeto de estudo de diversos trabalhos sobre a aristocracia portuguesa ${ }^{13}$. No que concerne à Casa

${ }^{9}$ Nuno Gonçalo Monteiro, O Crepúsculo..., cit., p. 95.

${ }^{10}$ Jean-Pierre Labatut, Les noblesses européennes de la fin do XV siécle à la fin do XVIII ${ }^{e}$ siécle, Paris, Presses Universitaires de France, 1978, p. 73-78; Antonio Domínguez Ortiz, Las Clases Privilegiadas en el Antiguo Regimen. Madrid, Ediciones ISTMO, 1979, p. 20-25; Maria de Lurdes Rosa, O Morgadio..., cit., p. 37-94 e Ignacio Atienza Hernández,"La memoria construida: Nobleza y Genealogia de la Casa y la Villa de Osuna", Apuntes, 2 (1998), p. 8-10.

${ }^{11}$ Rafael Bluteau, Vocabulario Portuguez e Latino, II, Coimbra, No Collegio das Artes da Companhia de Jesu, 1713, p. 172-174.

${ }^{12}$ Ignacio Atienza Hernández, "Pater Familias, Señor y Patrón: Oeconómica, Clientelismo e Patronato en el Antiguo Régimen" in Reyna Pastor (comp.), Relaciones de Poder, de Produccion y Parentesco en la Edad Media y Moderna, Madrid, Consejo Superior de Investigaciones Cientificas, 1990, p. 411-458; Daniela Frigo, “«Disciplina Rei Familiarae»: a Economia como Modelo Administrativo de Ancien Régime”, Penélope, 6 (1991), p. 47-62 e António Manuel Hespanha, "Carne de uma só carne: para uma compreensão dos fundamentos histórico-antropológicos da família na época moderna”, Análise Social, XXVIII (1993), p. 951-973.

${ }^{13}$ Maria Teresa Sena, A Casa de Oeiras e Pombal. Estado, Senhorio e Património, Tese de Mestrado em História, Lisboa, Faculdade de Ciências Sociais e Humanas da Universidade Nova de Lisboa, 1987; Maria Paula Marçal Lourenço, A Casa e o Estado do Infantado, 1654-1706. Formas e Práticas Administrativas de um Património Senhorial, Lisboa, Junta Nacional de Investigação Científica e Tecnológica, 1995 e Casa, Corte e Património das Rainhas de 
de Aveiro, embora deva ser assinalado o que foi escrito acerca dos seus poderes jurisdicionais e redes clientelares ${ }^{14}$, a ausência de estudos é bastante sentida ${ }^{15}$. Os poucos trabalhos sobre esta entidade senhorial dados à estampa focaram as suas gerações e a sua história familiar, mas sem abordar os aspetos de que o presente texto se ocupa ${ }^{16}$. As obras de António Caetano de Sousa ${ }^{17}$ e de Fernando de Castro e Silva Canedo ${ }^{18}$, no entanto, merecem ser destacadas pois não só enumeram as diversas gerações familiares, como também apresentam de forma mais ou menos completa as biografias dos seus elementos, motivo pelo qual constituem a fonte primária deste trabalho.

Nas páginas que se seguem serão analisados os destinos da primeira geração de descendentes dos indivíduos que administraram o conjunto de bens da Coroa doados por D. Manuel a D. Jorge de Lencastre, segundo duque de Coimbra, mestre das ordens militares de Avis e de Santiago e filho ilegítimo do rei D. João $\mathrm{II}^{19}$, e as comendas, alcaidarias-mores e senhorios destas milícias posteriormente

Portugal (1674-1750). Poderes, Instituições e Relações Sociais, Dissertação de Doutoramento em História Moderna, Lisboa, Faculdade de Letras da Universidade de Lisboa, 1999; Mafalda Soares da Cunha, A Casa de Bragança, 1560-1640. Práticas senhoriais e redes clientelares, Lisboa, Editorial Estampa, 2000; João Paulo Salvado, Nobreza Monarquia e Império. A Casa Senhorial dos Almotacés-mores do Reino, Dissertação de Doutoramento em História dos Descobrimentos e da Expansão Portuguesa, Lisboa, Faculdade de Ciências Sociais e Humanas da Universidade Nova de Lisboa, 2010 e "An Aristocratic Economy in Portugal in the First Half of the Seventeenth Century: The House of the Marquises of Castelo Rodrigo", e-Journal of Portuguese History, 9, 2 (Winter 2011), p. 35-67.

${ }^{14}$ Sérgio Soares da Cunha, "O ducado de Aveiro e a vila da Lousã no século XVIII (1732-1759)", Arunce, 11/12 (1996-1997), p. 37-68 e "Nobreza conimbricense e modos de governo político. Um ensaio municipal (1641-1724), Revista Portuguesa de História, XXXI/I (1996), p. 555-573; e Cristóvão Mata, O Poder Local em Penela (1640-1834), Coimbra, Palimage, 2014 e "A Estrutura Administrativa de Penela nos Séculos XVII e XVIII", in Margarida Sobral Neto (coord.), Penela. Um percurso pelo tempo, Coimbra, Palimage, 2015, p. 107-128.

${ }^{15}$ Cristóvão Mata, “A Casa de Aveiro: Poder e Património”, Revista Portuguesa de História, 44 (2013), p. 309-326.

${ }^{16}$ Carlos Ary dos Santos, "Estudos de Direito Nobiliárquico Português II. A Sucessão da Casa e Ducado de Aveiro", Armas e Troféus, VIII (1967); J. T. Montalvão Machado, Casa e Ducado de Aveiro e sua representação actual, Lisboa, Edição do Autor 1971 e Francisco Ferreira Neves, "A Casa e o Ducado de Aveiro. Sua origem, evolução e extinção", Arquivo do Distrito de Aveiro, XXXVIII (1972).

${ }^{17}$ António Caetano de Sousa, História da Casa Real Portugueza, XI, Lisboa, Na Regia Officina Sylviana, e da Academia Real, 1745, p. 1-369.

${ }^{18}$ Fernando de Castro da Silva Canedo, A Descendência Portuguesa de El-Rei D. João II, I, Lisboa, Edições Gama, 1945.

${ }^{19}$ António Caetano de Sousa, Provas da História Genealogica da Casa Real Portugueza, VI, Lisboa, Na Regia Officina Sylviana, e da Academia Real, 1748, p. 1-9. 
concedidos a D. João de Lencastre, primeiro duque de Aveiro ${ }^{20}$. A coerência que se pretende conferir a este estudo implica que se considerem também os filhos de quem esteve na linha imediata de sucessão, pelo que a população estudada é composta da prole dos duques de Coimbra, Aveiro e Torres Novas.

A incidência da análise nos séculos XVI e XVII deriva das especificidades desta casa senhorial após a fuga para Espanha do quarto duque de Aveiro, D. Raimundo de Lencastre, em 1659. No seguimento deste episódio, a Casa de Aveiro esteve sob administração régia durante a maior parte dos cem anos seguintes e, apesar da sua concessão a três senhores, não ocorreu a celebração de nenhum casamento nem foi gerado qualquer herdeiro sobre cujo percurso vida nos possamos debruçar. D. Pedro de Lencastre, arcebispo de Sidónia e inquisidor-geral, sucedeu ao duque D. Raimundo, seu sobrinho, em 1668, e o seu falecimento sem herdeiros, ocorrido cinco anos depois, provocou uma crise sucessória resolvida muito depois. Em 1732, a Casa de Aveiro foi sentenciada favoravelmente a D. Gabriel de Lencastre, sexto senhor deste título, que também faleceu sem sucessão, em $1745^{21}$.

Quanto à exclusão do sétimo e último duque de Aveiro, esta opção deve-se ao facto de os motivos que o conduziram à sucessão na Casa de Aveiro não corresponderem aos critérios nos quais se baseia a elaboração deste trabalho. Filho de D. Martinho de Mascarenhas, marquês de Gouveia e conde de Santa Cruz, D. José de Mascarenhas Silva e Lencastre entroncava na descendência dos terceiros duques de Aveiro muito remotamente. O seu casamento, celebrado a 21 de julho de 1739 com D. Leonor Tomásia de Távora e Lorena, filha do conde de Alvor, ocorreu fora do âmbito de uma estratégia familiar desenvolvida pela Casa de Aveiro. Além disso, nenhum dos seus dois filhos e quatro filhas, dos quais somente uma nasceu depois de D. José assumir a administração desta casa senhorial, tomou estado até à extinção da Casa de Aveiro, em 175922.

No que se refere à delimitação temática e cronológica do presente trabalho, também é oportuno referir que em 1679 a Casa de Aveiro foi julgada a favor de D. Maria de Guadalupe de Lencastre, filha de D. Jorge de Lencastre, duque de Torres

${ }^{20}$ Arquivo Nacional Torre do Tombo (Lisboa), Chancelaria de D. João III, Doações, ofícios e mercês, Livro 58, fls. 141v-143.

${ }^{21}$ António Caetano de Sousa, História..., XI, p. 147-177 e Maria Silveira Martins Ribas, "O Governo do Tribunal do Santo Ofício ao Tempo de D. Pedro de Lencastre (1671-1673). Garantir a Fé em Tempos Conturbados", Boletim do Arquivo da Universidade de Coimbra, XXVII (2014), p. 351-373.

${ }^{22}$ António Caetano de Sousa, Memorias Historicas e Genealogicas dos Grandes de Portugal, Lisboa, Na Regia Officina Sylviana, e da Academia Real, 1755, p. 125-135 e Fernando de Castro da Silva Canedo, A Descendência Portuguesa..., I, cit., p. 31-32. 
Novas, irmã de D. Raimundo e mãe de D. Gabriel. Todavia, esta senhora jamais prestou vassalagem ao rei de Portugal nem tomou pessoalmente posse da sua herança, como era requerido na sentença ${ }^{23}$. A sua inclusão neste trabalho ocorre no âmbito da sua filiação ao primogénito e presuntivo sucessor dos terceiros duques de Aveiro, sendo excluídos os percursos individuais e as estratégias matrimoniais dos seus filhos na medida em que este trabalho estabelece como unidade de análise a Casa de Aveiro e não a linhagem Lencastre.

Tabela 1 - Gerações da Casa de Aveiro

\begin{tabular}{|c|c|c|c|c|c|c|c|}
\hline & $\begin{array}{l}\text { D. } \\
\text { Jorge I }\end{array}$ & $\begin{array}{l}\mathrm{D} . \\
\text { João }\end{array}$ & $\begin{array}{c}\text { D. } \\
\text { Jorge II }\end{array}$ & $\begin{array}{l}\text { D. } \\
\text { Álvaro }\end{array}$ & $\begin{array}{c}\text { D. } \\
\text { Jorge III }\end{array}$ & $\begin{array}{c}\text { D. } \\
\text { Raimundo }\end{array}$ & Total \\
\hline $\begin{array}{l}\text { Número de Casa- } \\
\text { mentos }\end{array}$ & 1 & 1 & 1 & 1 & 2 & 1 & 7 \\
\hline Total de Filhos & 12 & 3 & 1 & 16 & 4 & 1 & 37 \\
\hline Casados & 3 & 2 & - & 3 & 1 & - & 9 \\
\hline Religiosos & 1 & - & - & 3 & - & - & 4 \\
\hline 言 Leigos & - & - & - & - & - & - & - \\
\hline Sem estado & - & - & - & 1 & - & - & 1 \\
\hline Indefinido & - & - & - & - & 1 & - & 1 \\
\hline Ilegítimos & 3 & 1 & - & - & - & 1 & 5 \\
\hline Total de Masculinos & 7 & 3 & - & 7 & 2 & 1 & 20 \\
\hline Casadas & - & - & 1 & 3 & 1 & - & 5 \\
\hline$\dddot{\mathscr{Z}}$ Religiosas & 4 & - & - & 4 & - & - & 8 \\
\hline Leigas & - & - & - & - & - & - & - \\
\hline Sem estado & - & - & - & 2 & 1 & - & 3 \\
\hline Indefinidas & - & - & - & - & - & - & - \\
\hline Ilegítimas & 1 & - & - & - & - & - & 1 \\
\hline Total de Femininas & 5 & - & 1 & 9 & 2 & - & 17 \\
\hline
\end{tabular}

A tabela exposta atrás apresenta as seis gerações que compõem a população em estudo e reporta-se a trinta e sete indivíduos do sexo masculino (20) e feminino (17). O número médio de filhos nascidos por senhor é de $6,16 \mathrm{e}$ reproduz a disparidade dos nascimentos de indivíduos do sexo masculino

${ }^{23}$ Luís de Moura Sobral "Maria Guadalupe de Lencastre (1630-1715). Cuadros, Libros y Aficiones de una duquesa ibérica", Quintana, 8 (2009), p. 61-73; "D. Maria Guadalupe de Lencastre (1630-1715): a cultura literária e artística de uma duquesa luso-espanhola da época da Restauração", Siglo de Oro. Relações Hispano-Portuguesas no século XVII. Suplemento de Colóquio/Letras, 178 (2011), p. 139-149 e "De la libreria, contemplando al Cielo. Imagens e cultura visual em livros de ciência e técnicas da Biblioteca de D. Maria Guadalupe de Lencastre (1630-1715), Duquesa de Aveiro", Ágora. Estudos Clássicos em Debate, 14.1 (2012), p. 169-201. 
$(3,33)$ e feminino $(2,83)$. Considerando somente os nascimentos legítimos $(31)$, aquele valor decresce para 5,16 e inverte a proporção do nascimento de filhos $(2,5)$ e de filhas $(2,66)$. Reduz-se ainda mais se a totalidade dos descendentes legítimos for distribuída pelo número de casamentos realizados $(4,43)$, mantendo o desequilíbrio ligeiramente favorável para o nascimento de crianças do sexo feminino $(2,29)$ relativamente às do sexo masculino $(2,14)$.

Esta diminuição deveu-se à ausência de descendentes do primeiro casamento do duque de Torres Novas, D. Jorge III, certamente propiciada pelo falecimento precoce de D. Ana de Ória, sua primeira esposa ${ }^{24}$, e do casamento de D. Raimundo, que constituem os dois únicos matrimónios estéreis. Excluindo estes dois casos, a média situa-se nos 6,2 filhos por casamento. Porém, não se aproxima da moda dos nascimentos no âmbito do matrimónio, pois o número de filhas e de filhos nascidos por casamento é predominantemente inferior a cinco. Os dois casos que superaram este valor, revelando uma elevada fertilidade, correspondem a longos períodos de vida conjugal, nomeadamente aos casamentos dos duques de Coimbra, D. Jorge I e D. Beatriz, e dos terceiros duques de Aveiro, D. Álvaro e D. Juliana. No entanto, a durabilidade de um casamento não explica por inteiro a geração de muitos descendentes.

Tabela 2 - Relação entre anos de casamento e filhos legítimos

\begin{tabular}{|lccccc} 
& D. Jorge I & D. João & D. Jorge II & D. Álvaro & D. Jorge III \\
Ano do casamento & 1500 & 1547 & 1568 & 1588 & 1629 \\
Falecimento de um nubente & 1535 & 1570 & 1578 & 1626 & 1632 \\
Duração do casamento (anos) & 35 & 23 & 10 & 38 & 4 \\
Número de filhos & 8 & 2 & 1 & 16 & 4 \\
$\begin{array}{l}\text { Distribuição dos filhos pela } \\
\text { duração do casamento }\end{array}$ & 4,4 & 11,5 & 10 & 2,4 & 1 \\
\hline
\end{tabular}

A tabela anterior demonstra que D. João esteve casado durante vinte e quatro anos e gerou apenas dois filhos legítimos, muito possivelmente devido à idade avançada com que casou. A distribuição de nascimentos pelos anos de vida matrimonial indica que o menor ritmo de geração de herdeiros correspondeu ao seu casamento, no qual foi gerado um filho a cada 11,5 anos, sendo imediatamente seguido pelo seu primogénito e segundo duque de Aveiro, D.

\footnotetext{
${ }^{24}$ A celebração do casamento de D. Jorge III com D. Ana de Ória ocorreu a 11 de agosto de 1618. António Caetano de Sousa refere que, aquando da vinda de D. Filipe II a Lisboa, em 1619, D. Ana falecera havia dois meses - cf. Biblioteca da Ajuda (Lisboa), 51-IX-8, fls. 165-173v e História..., XI, cit., p. 95 e 115.
} 
Jorge II, com apenas uma filha nascida ao longo de um casamento que durou dez anos. Em contrapartida, D. Jorge III gerou quatro filhos durante igual número de anos que esteve casado com a segunda duquesa de Torres Novas, D. Álvaro um filho a cada 2,4 anos e D. Jorge I um a cada 4,4.

O destino dos ilegítimos não é do foro do presente texto, mas não deixa de ser interessante notar que, à exceção do filho do duque D. Raimundo, todos correspondem a filhos do duque de Coimbra e do primeiro duque de Aveiro. Neste sentido, é possível que a incidência da ilegitimidade na primeira metade do século XVI se reportasse a nascimentos ocorridos em situações de viuvez ou pré-matrimonial (naturais) e não somente a crianças nascidas de relações adúlteras (bastardos) ${ }^{25}$. O falecimento precoce da duquesa de Coimbra (1535) e o casamento tardio de D. João (1547) sustentam a hipótese, mas a escassez de dados biográficos sobre aqueles cinco indivíduos não permite a sua confirmação.

Tabela 3 - Características e percursos dos filhos

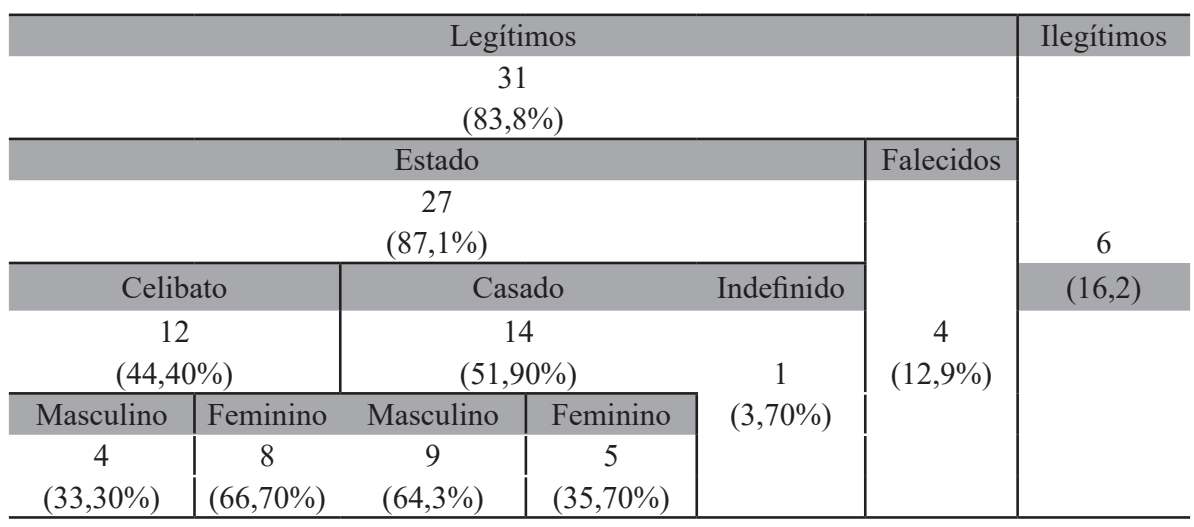

O número de filhas e filhos legítimos que não atingiram a idade adulta é pouco expressivo e reporta-se aos descendentes dos terceiros duques de Aveiro (3) e dos duques de Torres Novas (1). A reduzida amostra deste grupo não permite detetar um maior investimento nos filhos em detrimento das filhas, como sugeriu James L. Boone ${ }^{26}$, embora a correspondência que existe entre $o$ número das crianças falecidas e os casamentos dos quais nasceram bastantes filhos (um por ano ou a cada 2,4 anos) aponte para a possibilidade de que tenham

${ }^{25}$ Enrique Soria Mesa, La nobleza en la España Moderna. Cambio y continuidad, Madrid, Marcial Pons, 2011, p. 186.

${ }^{26}$ James L. Boone, "Parental Investment...”, cit., p. 861. 
ocorrido complicações de natureza gestacional ou outras que eventualmente comprometessem as hipóteses de aqueles menino e meninas alcançarem a vida adulta.

Não dispomos de informações biográficas de apenas um elemento do grupo dos indivíduos que atingiram a maioridade. Trata-se de um filho de D. Jorge III chamado D. João Manrique de Lencastre e Cardenas, nascido em 1633 e falecido no ano de 1659. Sobre a sua vida, a obra de António Caetano de Sousa apenas registou que pretendeu suceder à Casa de Maqueda, não referindo se casou, se se manteve em celibato ou se ingressou na vida religiosa ${ }^{27}$. Ao excluí-lo do grupo de indivíduos que alcançaram a vida adulta e tomaram estado, verifica-se que o número de casamentos (54\%) é ligeiramente superior aos ingressos religiosos $(46 \%)$ e que a relação entre homens e mulheres que casaram ou ingressam na vida religiosa é rigorosamente inversa.

O grupo de celibatários é composto pelos descendentes de casamentos bastante férteis e predominantemente constituído por mulheres. A primeira característica deve-se ao facto de a sucessão do duque de Coimbra e do terceiro duque de Aveiro estar assegurada aquando do seu nascimento, correspondendo os quatro celibatários a filhos posicionados em último lugar na ordem de nascimento: D. Jaime de Lencastre foi o quarto filho varão dos duques de Coimbra e os restantes três homens, filhos dos terceiros duques de Aveiro, foram precedidos pelos nascimentos de D. Jorge e D. Afonso ${ }^{28}$.

A condição de ultimogénitos certamente justifica que os respetivos futuros fossem decididos muito precocemente. Na descrição que escreveu do casamento dos duques de Torres Novas, celebrado em 1618, João Baptista Lavanha mencionou a presença de D. Pedro e de D. António, o primeiro nascido a 20 de abril de 1608 e o segundo a 4 de agosto de $1611^{29}$, informando serem «estudantes e averão de ser clerigos querendo Deos» ${ }^{30}$. Por outro lado, a forte expressividade feminina no grupo dos celibatários dever-se-ia à exigência de grandes investimentos em dotes, bem como a outros fatores. Muito embora uma das filhas do duque de Coimbra tenha sido considerada para casar com o

${ }^{27}$ António Caetano de Sousa, História ..., XI, cit., p. 118-119.

${ }^{28}$ Batizados a 13 de abril de 1594 e a 18 de junho de 1597 - cf. Arquivo Distrital de Setúbal, Paróquia de São Lourenço de Azeitão, Registo de Batismos, 1589-1-29/1604-10-10, fls. 22 e 35v.

${ }^{29}$ ADS, Paróquia de São Lourenço de Azeitão, Registo de Batismos, 1604-5-9/1628-6-9, fls. $27 \mathrm{v}$ e 35 .

${ }^{30}$ BA, 51-IX-8, fl. 170. 
infante D. Luís ${ }^{31}$, o celibato foi o destino adotado por todas as suas descendentes e poderá ter decorrido das limitações do mercado nupcial interno ${ }^{32}$.

$\mathrm{O}$ ingresso das filhas de D. Álvaro e de D. Juliana na vida religiosa terá obedecido à lógica que encaminhou os seus irmãos para o mesmo destino. A primeira das filhas dos terceiros duques de Aveiro que alcançaram a vida adulta, D. Madalena, casou com o conde de Faro. As que se seguiram na ordem de nascimento, D. Violante, D. Luísa e D. Beatriz, tomaram o estado religioso e a seguinte, D. Violante $\mathrm{II}^{33}$, casou com o conde de Basto. D. Mariana, a sexta filha, também tomou estado de religiosa e, por fim, D. Maria casou-se com o marquês de Gouveia, em $1625^{34}$. Não existe, pois, nenhum padrão que relacione a ordem de nascimento daquelas três filhas com o estado matrimonial tomado, mas alguns pormenores sugerem tratar-se de casos excecionais.

Uma carta do duque D. Álvaro, datada de 9 de setembro de 1622, refere que D. Madalena se casara em segredo ${ }^{35}$, porventura contrariando o futuro que lhe fora destinado. Quanto às suas duas irmãs, o posicionamento de ambas na ordem de nascimento não terá constituído o critério que decidiu os seus destinos. Considerando a possibilidade de as irmãs mais velhas haverem tomado o estado religioso antes da celebração dos matrimónios, os casamentos do conde de Basto e do marquês de Gouveia com estas senhoras dever-se-iam ao facto de serem as únicas filhas disponíveis para se consorciarem. Além disso, dado tratar-se de fidalgos portugueses largamente beneficiados pela $\mathrm{Coroa}^{36}$, é provável que os casamentos visassem a celebração de alianças com nobres próximos dos monarcas de Habsburgo.

${ }^{31}$ António Caetano de Sousa, Historia..., XI, cit., p. 32.

${ }^{32}$ Sobre o universo dos titulares portugueses na primeira metade do século XVI, ver Luís Filipe Oliveira e Miguel Jasmins Rodrigues, "Um Processo de Reestruturação do Domínio Social da Nobreza. A Titulação na 2. ${ }^{a}$ Dinastia”, Revista de História Económica e Social, 22 (1988), p. 77-114 e João Cordeiro Pereira, “A Estrutura Social e o seu devir” in Joel Serrão e A. H. de Oliveira Marques (Dir.), Nova História de Portugal, V, João José Alves Dias (Coord.), Do Renascimento à Crise Dinástica, Lisboa, Editorial Presença, 1998, p. 315-323.

${ }^{33}$ Batizadas a 9 de julho de 1591, 6 de março de 1593, 10 de junho de 1600, 20 de novembro de 1602 e 9 de maio de 1604, respetivamente - cf. ADS, Paróquia de São Lourenço de Azeitão, Registo de Batismos, 1589-1-29/1604-10-10, fl. 12, 17, 47v, 58 e Registo de Batismos, 1604$-5-9 / 1628-6-9$, fl. 1.

${ }^{34}$ António Caetano de Sousa, Historia ..., X, cit., p. 141.

${ }^{35}$ Biblioteca Nacional de España (Madrid), MSS. 9390.

${ }^{36}$ Rute Pardal, "Serviço Político e Ascensão Social: o percurso dos Castro ao tempo da dominação filipina (1580-1640) ", in Anales del VII Congreso de la Asociación de Demografía Histórica, Granada, Universidad de Granada, 2004. p. 5-18 e Anselmo Braancamp Freire, Brasões da Sala de Sintra, II, Coimbra, Imprensa da Universidade, 1927, p. 31-32. 
A vida religiosa constituiu o destino natural dos filhos e filhas celibatários de D. Jorge I e de D. Álvaro. Os homens seguiram quase invariavelmente o clero secular, sendo o único religioso regular D. João de Lencastre, terceiro filho de D. Álvaro e de D. Juliana, que ingressou na ordem de São Domingos e foi prior de um convento de Setúbal ${ }^{37}$. No caso de D. Jaime, a sua carreira eclesiástica iniciou-se à custa dos recursos da casa, tendo sido apresentado no priorado da igreja do Salvador de Torres Novas ${ }^{38}$, da qual o duque de Coimbra era padroeiro. O que não significa que noutras circunstâncias as carreiras eclesiásticas não se iniciassem sob patrocínio régio, como ilustra a referência de uma carta anónima à petição da terceira duquesa de Aveiro para o rei apresentar D. Pedro numa igreja de Lisboa ${ }^{39}$.

Ainda que o provimento de parentes em dignidades religiosas tenha ocorrido, o exercício do direito de padroado detido por uma casa senhorial destinava-se sobretudo a beneficiar clientelas e não a reservar priorados ou benefícios para os seus secundogénitos ${ }^{40}$. Do mesmo modo, o patrocínio nobiliárquico a conventos e mosteiros constituía um expediente de afirmação simbólica do poder das casas senhoriais. Podia ainda significar a diversificação dos mecanismos de remuneração de criados, mediante por exemplo a criação de capelas funerárias para os seus servidores ou de espaços de recolhimento para as filhas celibatárias destes, mas era quase sempre um investimento na glorificação dos patronos materializado na instituição de panteões familiares ${ }^{41}$.

O contrato assinado entre D. João de Lencastre e o mosteiro de São Domingos de Coimbra em 1567 é revelador das intenções que justificavam o patrocínio conventual. O duque de Aveiro comprometia-se a financiar a construção de um novo edifício exigindo, em contrapartida, que a capela-mor fosse reservada para receber o sepulcro de ambos os duques e dos seus filhos e sucessores ${ }^{42}$. Redigido cinco anos depois, o testamento de D. João confirmou aquela disposição e acrescentou a intenção de se trasladarem para o referido mosteiro os restos mortais de D. Jorge I e do rei D. João II, seus pai e avô, além

${ }^{37}$ António Caetano de Sousa, Historia..., XI, cit., p. 102.

${ }^{38}$ ANTT, Memórias Paroquiais, 37, n. ${ }^{\circ}$ 77A, fl. 141.

${ }^{39}$ ANTT, Núcleo Antigo 879, n. ${ }^{\circ} 212$.

${ }^{40}$ Mafalda Soares da Cunha, A Casa de Bragança..., cit., p. 348-359.

${ }^{41}$ Ángela Atienza López. "Cuestiones sobre las relaciones de patronazgo conventual en la España moderna”, in José María Imízcoz Beunza e Andoni Artola Renedo (coord.), Patronazgo y clientelismo en la monarquía hispánica (siglos XVI-XIX), Bilbao, Universidad del País Vasco, 2016, p. 109-134.

${ }^{42}$ Arquivo da Universidade de Coimbra, Mosteiro de São Domingos, Livro 13, fls. 131v-140v. 
de disponibilizar rendas para o pagamento de dotes a órfãs originárias dos seus senhorios e de tenças a estudantes pobres da mesma proveniência ${ }^{43}$.

Apesar de se desconhecer o paradeiro de documentos semelhantes àquele diploma e dos testamentos das gerações seguintes ${ }^{44}$, as escassas referências ao patrocínio conventual apontam somente no sentido da criação de panteões. Naquele caso específico, o investimento num espaço destinado a acolher os restos mortais da ascendência e descendência do primeiro duque de Aveiro e identificado exteriormente com o seu brasão de armas poderia visar objetivos mais específicos, como o de assinalar a legitimidade da sucessão no título de duque de Coimbra, que D. João e os seus sucessores sempre pretenderam fazer valer $^{45}$. Mas durante o século XVII, por exemplo, o convento da Arrábida foi o local escolhido para o sepultamento de D. Álvaro, D Juliana e D. Pedro, sendo este cenóbio desde há muito alvo da estima dos duques de Aveiro e continuando a sê-lo nas vésperas da extinção da sua casa ${ }^{46}$.

Neste sentido, o investimento em casas religiosas não correspondeu à instituição de espaços de reclusão para as suas filhas celibatárias: a opção pelas casas religiosas onde estas se recolheram obedeceu a outros critérios. Muito concretamente, à localização destes conventos junto de espaços de residência ducal, não obstante a itinerância que caracterizou as cortes régias e senhoriais do Renascimento ${ }^{47}$. Muita documentação da primeira metade do século XVI confirma a deambulação do duque de Coimbra por terras das ordens militares, mas revela também períodos de fixação mais ou menos prolongados em Lisboa e Setúbal ${ }^{48}$, que outras fontes confirmam.

A 14 de abril de 1522, D. João III ordenou a D. Jorge que «fosse das pousadas, de onde em Santos pousava, para as suas pousadas de Lisboa, e que até à

${ }^{43}$ ANTT, Ordem de Santiago e Convento de Palmela, maço 7, n. ${ }^{\circ} 522 \mathrm{~A}$, fls. 1-14v.

${ }^{44}$ Datado de 1745, o testamento de D. Gabriel encontra-se incompleto - ANTT, Ordem dos Pregadores, Mosteiro de Jesus de Aveiro, mç. 1, fls. 4-7.

${ }^{45}$ António Caetano de Sousa, Provas..., VI, cit., p. 36-45 e BNE, MSS. 1439, fl. 279v.

${ }^{46}$ Frei António da Piedade, Espelho de Penitentes e Chronica da Provincia de Santa Maria da Arrabida, I, Lisboa, Na Officina de Joseph Antonio da Sylva, 1728, p. 84-95 e BA, 54-XI45, n. ${ }^{\circ} 8$, passim.

${ }^{47}$ John Adamson, "The making of the Ancien-Régime Court”, in John Adamson (ed.), The princely courts of Europe. Ritual, Politics and Culture under the Ancien Régime (1500-1750), London, Weiden \& Nicolson, 1999, p. 7-41.

${ }^{48}$ A título de exemplo, vide ANTT, Corpo Cronológico, Parte I, mç. 67, n. ${ }^{\circ} 1 ;$ mç. 78, n. ${ }^{\circ}$ 98 e Parte II, mç. 5, n. ${ }^{\circ} 76$; mç. 10,122 ; mç. 12 , n. ${ }^{\circ} 15$ e 142; mç. 13, n. ${ }^{\circ} 30,68$ e 69; mç. 15 ,

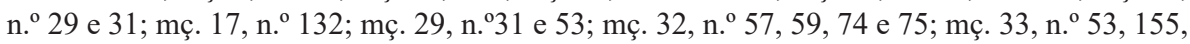
156; mç. 39, n. ${ }^{\circ} 32$ e 117 ; mç. 47, n. ${ }^{\circ} 101,159$ e 160 ; mç. 57, n. ${ }^{\circ} 140$; mç. 59, n. ${ }^{\circ} 48$; mç. 63 , n. ${ }^{\circ} 116$; mç. 68 , n. ${ }^{\circ} 79$; mç. $101,{ }^{\circ}{ }^{\circ} 69$; mç. 102 , n. ${ }^{\circ} 137$; mç. 113 , n. ${ }^{\circ} 17$; mç. 124 , n. ${ }^{\circ} 85 ;$ mç. 147 , n. ${ }^{\circ} 10 ;$ mç. 165 , n. ${ }^{\circ} 105$. 
terça-feira seguinte se saísse delas, e da cidade se fosse para sua casa $\gg^{49}$. Apesar de não se especificar qual a casa a que o rei se reportava, esta situar-se-ia em Setúbal. Nesta vila, junto à igreja de São Julião, existia um palácio da ordem de Santiago, depois herdado pelos seus sucessores enquanto alcaides-mores da $v_{\text {vila }}{ }^{50}$. Esta hipótese é reforçada pelo facto de também existir um regimento de aposentadoria, datado de 1508, no qual foram enunciadas as obrigações dos habitantes de Setúbal para com D. Jorge e os moradores da sua casa em matéria de alojamento e alimentação ${ }^{51}$.

Quanto à casa de Santos, tratava-se de um paço situado na zona extramuros da cidade e localizado defronte ao convento da Esperança ${ }^{52}$. O local de redação de muitos documentos redigidos ao tempo dos duques D. João e D. Jorge II revela que foi esta a sua residência permanente, bem como os registos paroquiais da freguesia de Santos-o-Velho e os respetivos assentos de batismo e de óbito de moradores e criados dos duques de Aveiro. Por sua vez, nos finais do século XVI, os duques D. Álvaro e D. Juliana estabeleceram-se em Azeitão ${ }^{53}$, sendo a sua permanência comprovada também pelos registos paroquiais de São Lourenço de Azeitão referentes aos seus filhos e filhas e a vários criados da sua casa.

Tabela - Destino dos celibatários

\begin{tabular}{lccccccc}
\hline & \multicolumn{3}{c}{ Masculinos } & \multicolumn{5}{c}{ Femininos } \\
Filiação & Secular Regular & Total & $\begin{array}{c}\text { Conv. de São } \\
\text { João (Setúbal) }\end{array}$ & $\begin{array}{c}\text { Most. da } \\
\text { Esperança } \\
\text { (Lisboa) }\end{array}$ & $\begin{array}{c}\text { Conv. da Madre } \\
\text { de Deus (Lisboa) }\end{array}$ & Total \\
D. Jorge I & 1 & - & 1 & 3 & 1 & - & 4 \\
D. Álvaro & 2 & 1 & 3 & 2 & - & 2 & 4 \\
\hline
\end{tabular}

Conforme demonstra a tabela apresentada em cima, o destino das filhas celibatárias dos duques de Coimbra e Aveiro correspondeu a ingressos em conventos localizados em Lisboa e Setúbal. D. Helena de Lencastre, filha de

${ }^{49}$ Ernesto de Campos de Andrada, Relações de Pero de Alcáçova Carneiro, conde de Idanha do tempo que ele e seu pai, António Carneiro, serviram de secretários (1515-1568), Lisboa, Imprensa Nacional de Lisboa, 1937, p. 218-219. Realces nossos.

${ }^{50}$ ANTT, Ordem de Santiago e Convento de Palmela, Livro 148, fl. 74 e Livro 202, fl. 23.

${ }^{51}$ ANTT, Leitura Nova, Livro 12, fls. 296-300.

${ }_{52}$ Joel Mata, A Comunidade Feminina da Ordem de Santiago. A comenda de Santos em finais do século XV e no século XVI. Um Estudo Religioso, Económico e Social, Porto, Fundação Eng. António de Almeida, 2007 e A. Vieira da Silva, "O Mosteiro da Esperança", Revista Municipal, 45 (1945), p. 11-22.

${ }^{53}$ Frei Nicolau de Oliveira, Livro das Grandezas de Lisboa, Lisboa, Jorge Rodrigues, 1620, p. 88. 
D. Jorge, sucedeu à sua avó paterna, D. Ana de Mendonça, como comendadeira do mosteiro da Esperança, enquanto as restantes filhas dos duques de Coimbra e Aveiro recolheram-se no convento de São João de Setúbal. Por fim, duas outras filhas de D. Álvaro e D. Juliana entraram no convento da Madre de Deus de Lisboa, reforçando a ideia de que a sua localização justificaria a escolha. Nestas circunstâncias, a reclusão das filhas em casas religiosas não significava obrigatoriamente o seu afastamento da casa onde haviam nascido.

Os homens sobrepõem-se claramente às mulheres no conjunto dos descendentes que contraíram matrimónio, perfazendo cerca de dois terços. $\mathrm{O}$ investimento no casamento de secundogénitos implicava a disponibilidade de recursos associados à casa, sendo as possibilidades ou as necessidades de cada geração que justificaram a sua concretização. A primeira situação é demonstrada pelo percurso dos segundo e terceiro filhos do duque de Coimbra e mestre das ordens de Avis e Santiago, milícias a cujos bens se recorreu para se lhes dar estado ${ }^{54}$. Assim, a concessão de rendimentos que garantissem o condigno sustento dos filhos de D. Jorge não significou um investimento que tenha implicado a perda dos bens da Coroa ou patrimoniais que constituíam a sua casa.

Em sentido inverso, a reduzida fertilidade do casamento do primeiro duque de Aveiro e a necessidade de garantir uma segunda linha de sucessão terão motivado o investimento no matrimónio do segundo e último filho, D. Pedro Dinis de Lencastre. Em 1559, o duque D. João adquiriu a capitania brasileira de Porto Seguro para deixar ao secundogénito, reservando-lhe posteriormente as suas comendas de Santiago do Cacém e de Sines ${ }^{55}$. O falecimento precoce de D. Pedro, ocorrido a 23 de setembro de $1675^{56}$, provocou o ingresso da capitania na casa do duque de Aveiro ${ }^{57}$. No século XVII, o duque D. Álvaro concedeu a donataria ao seu secundogénito. $\mathrm{O}$ rei derrogou a pretensão, mas investiu D. Afonso na dignidade de comendador-mor da ordem de Santiago e,

${ }^{54}$ D. Afonso e D. Luís administraram várias comendas e foram nomeados comendadoresmores das ordens de Santiago e de Avis - cf. Maria Cristina Gomes Pimenta, As Ordens de Avis e de Santiago na Baixa Idade Média. O Governo de D. Jorge, Câmara Municipal de Palmela, 2002, p. 304 e 520.

${ }^{55}$ António Caetano de Sousa, Provas..., VI, cit., p. 67-77; ANTT, Ordem de Santiago e Convento de Palmela, maço 7, n. ${ }^{\circ}$ 522A, fls. 9-9v e Gavetas, Gaveta 5, mç. 1, fl. 1.

${ }^{56}$ ANTT, Paróquia de Santos-o-Velho, Livro de Registos Mistos, 1566/1678, fl. 104.

${ }^{57}$ Pedro de Magalhães Gândavo, Tratado da terra do Brasil, Brasília, Edições do Senado Federal, 2008, p. 43; Fernão Cardim, Narrativa Epistolar de uma viagem e missão jesuítica, Lisboa, s.n., 1817, p. 25 e Gabriel Soares de Sousa, Tratado Descriptivo do Brasil em 1587, Rio de Janeiro, Typ. Universal de Laemmert, 1851, p. 65. 
por ocasião do seu casamento com D. Ana de Sande, outorgou-lhe também o título de marquês de Porto Seguro ${ }^{58}$.

Este último aspeto é interessante de referir na medida em que demonstra ser a celebração de casamentos acompanhada de doações régias: o assentamento do título de duque de Aveiro foi doado a D. João alguns meses após a celebração do seu casamento, em 1547, embora usasse o título desde os inícios da década de $1530^{59}$; poucos dias antes da celebração do casamento de D. Álvaro e D. Juliana, em setembro de 1588, foram concedidos os títulos de duque de Torres Novas para o seu primogénito e de marquês de Torres Novas para o filho deste ${ }^{60}$; sintomaticamente, o casamento de D. Jorge I com D. Beatriz realizouse a escassos dias após a doação das terras do ducado de Coimbra e da vila de Torres Novas ${ }^{61}$. Conforme a associação que Rafael Bluteau estabeleceu entre o termo casa e o estado matrimonial, tratava-se de «por ao casado sua casa» $\rangle^{62}$.

O casamento de mulheres ocorreu em menor número e correspondeu a apenas um terço do conjunto de descendentes que contraíram matrimónio. Como atrás foi defendido, os casamentos das três filhas de D. Álvaro terão constituído a exceção à regra que orientou o destino tomado pelas mulheres. No caso de D. Juliana, única filha dos segundos duques de Aveiro, a realização do seu casamento deveu-se à falta de descendência masculina e à indicação expressa por D. Jorge II em testamento. Apesar das tentativas de uni-la a nobres espanhóis ${ }^{63}$, casou com D. Álvaro de Lencastre, filho do comendador-mor D. Afonso e primo do duque D. Jorge II, sendo o único casamento celebrado com um membro da mesma linhagem ${ }^{64}$.

${ }^{58}$ António Caetano de Sousa, Historia..., XI, cit., p. 178-179.

${ }^{59}$ ANTT, Chancelaria de D. João III, Doações, ofícios e mercês, Livro 15, fl. 97v. O título terá sido concedido por D. João III em data anterior a 1535 , pois as crónicas régias assim intitulam D. João ao referir a jornada do infante D. Luís a Barcelona. A datação é corroborada por uma carta, datada de 11 de maio, pela qual o duque de Aveiro constituiu o conde de Vimioso como seu procurador às Cortes de Torres Novas, recuando mais um ano ao considerar-se uma relação de comendas da ordem de Santiago, na qual é mencionado. D. João casou-se com D. Juliana a 1 de fevereiro de 1547 e o assentamento ducal foi doado a 26 de julho, embora a carta de doação do título fosse passada somente dez anos depois - cf. António Caetano de Sousa, Historia..., XI, cit., p. 44-45 e 64-67; ANTT, Corpo Cronológico, Parte 2, mç. 200, n. ${ }^{\circ}$ 106; Gavetas, Gaveta 4, mç. 1, n. ${ }^{\circ} 9$ e Chancelaria de D. João III, Doações, ofícios e mercês, Livro 15, fl. 97v.

${ }^{60}$ António Caetano de Sousa, Provas..., VI, cit., p. 77-78 e Academia das Ciências de Lisboa, MSS. 289, fls. 463 e seguintes.

${ }^{61}$ António Caetano de Sousa, Historia..., XI, cit., p. 13.

${ }^{62}$ Rafael Bluteau, Vocabulario..., II, cit., p. 174.

${ }^{63}$ ANTT, Núcleo Antigo 880, n. ${ }^{\circ} 313$.

${ }^{64}$ António Caetano de Sousa, Historia..., XI, cit., p. 71-73 e 83-93. 
Este casamento, além de ter sido o único que uniu membros da linhagem Lencastre, foi dos poucos celebrados com filhos de nobres não titulados. $\mathrm{O}$ segundo casamento contraído nestas circunstâncias foi celebrado por D. Luís de Lencastre, terceiro filho do duque de Coimbra e comendador-mor de Avis, e D. Madalena de Granada, aia da rainha D. Catarina e filha do governador da Galiza. Os restantes doze casamentos que se realizaram durante os séculos XVI e XVII corresponderam a matrimónios que uniram as filhas e os filhos dos duques de Coimbra, Aveiro e Torres Novas a descendentes de duques, marqueses e condes de origem portuguesa e espanhola ou de outros espaços da Monarquia Católica.

Um estudo recente sobre os casamentos mistos celebrados no decurso da terceira dinastia demonstra que a celebração destes matrimónios ocorreu sob os auspícios régios, pretendendo a Coroa promover a integração das nobrezas do Império de Habsburgo ${ }^{65}$. Os titulados portugueses não aderiram ao projeto com grande entusiasmo, mas a Casa de Aveiro constituiu uma das raras exceções. Esta estratégia familiar contrastou com a orientação tomada durante o século XVI, quando dos seis casamentos realizados somente dois foram contraídos com filhas de nobres espanhóis: o casamento de D. Luís, acima mencionado, e o de D. Jorge II com D. Madalena Teles de Girón, filha do conde de Ureña e irmã do duque de Osuna.

Os seis casamentos dos filhos e filha dos terceiros duques de Aveiro e dos duques de Torres Novas negociados fora de Portugal confirmam a adesão desta casa ao projeto filipino. Os três filhos de D. Álvaro e D. Juliana uniram-se a quatro mulheres originárias de vários domínios da coroa espanhola: o duque de Torres Novas, D. Jorge II, casou por duas vezes com as filhas do príncipe de Melfi e do duque de Maqueda; D. Afonso, marquês de Porto Seguro, consorciouse com a filha do marquês de Valdefuentes e D. Luís uniu-se à filha do marquês de Malagón. Esta tendência manteve-se na geração seguinte: o casamento de D. Raimundo foi celebrado com uma filha do príncipe de Ligne e o de D. Maria de Guadalupe, sua irmã, realizado com D. Manoel Ponce de León, duque de Arcos. No entanto, ambos os casos distinguem-se dos exemplos mencionados anteriormente, pois ocorreram somente após a fuga do duque de Aveiro para Espanha.

A rejeição deste senhor à causa brigantina já foi referida por diversas vezes, mas agora convém referir que considerá-la uma manifestação de fidelidade

\footnotetext{
${ }^{65}$ Mafalda Soares da Cunha, "Titulos portugueses y matrimonios mixtos en la Monarquía Católica”, in Bartolomé Yun Casalilla (dir.), Las Redes del Imperio: Élites sociales en la articulación de la Monarquía Hispánica, 1492-1714, Madrid, Marcial Pons, 2009, p. 205-231.
} 
a D. Filipe III pode ser precipitado. A 1 de dezembro de 1640, a duquesa de Torres Novas, como tutora e administradora dos bens do seu filho, governava interinamente a Casa de Aveiro. As notícias da aclamação brigantina foram recebidas com resistência em alguns dos senhorios ducais e D. Ana Maria foi obrigada pelo rei a recolher-se em Penela ${ }^{66}$. Anos depois, alertava-se o rei para o perigo que representava o facto de o duque ser criado pela duquesa de Torres Novas e pelas suas criadas castelhanas ${ }^{67}$. Não obstante estas indicações, a troca epistolar entre a rainha, o conde de Soure e o duque de Aveiro sugere que a discórdia resultou dos impedimentos que D. Luísa de Gusmão levantou ao casamento que D. Raimundo desejava celebrar ${ }^{68}$.

$\mathrm{O}$ confronto entre o duque e a rainha devido à rejeição do casamento não foi inédita, embora nenhum dos episódios anteriores resultasse num desfecho tão trágico quanto a rutura protagonizada por D. Raimundo em 1659: pouco depois do falecimento do rei D. Manuel, D. Jorge de Lencastre e o marquês de Torres Novas foram expulsos da corte devido às alegações de D. João acerca do suposto casamento realizado em segredo com D. Guiomar Coutinho, filha do conde de Marialva prometida ao infante D. Fernando; anos depois, o duque de Coimbra também foi obrigado a recolher-se em Setúbal devido ao escândalo que provocava a sua insistência em casar com D. Maria Manuel, dama da rainha D. Catarina ${ }^{69}$.

A reprodução de ambos os episódios nas crónicas dos reinados de D. Manuel e D. João III, nos termos em que foi realizada, poderá ter constituído «um objecto de propaganda sistemática» contra D. Jorge e D. João ${ }^{70}$. De momento não interessa averiguar a veracidade dos pormenores relatados, mas é interessante observar as alegações de D. Fernando Coutinho relativamente aos interesses do marquês de Torres Novas, a quem acusava de cobiçar a sua fazenda ${ }^{71}$. Muito embora as circunstâncias em que D. Guiomar se encontrava fossem excecionais, pois era filha única e universal herdeira do conde de Marialva, o episódio é revelador do quão interessante podia ser um casamento.

${ }^{66}$ Mafalda Wagner de Moura, A Casa de Vila Real e a Conspiração de 1641 contra D. João IV, Lisboa, Colibri, 2007, p. 132-134.

${ }^{67}$ BA, 51-IX-6, n. ${ }^{\circ} 175$, fls. 349-349v.

${ }^{68}$ ANTT, Manuscritos da Livraria, Livro 1145, fls. 1-5.

${ }^{69}$ António Caetano de Sousa, Historia..., XI, cit., p. 23-30 e 42-43 e Provas..., VI, cit., p. 21-29.

${ }^{70}$ Sanjay Subrahmanyam, A carreira e a lenda de Vasco da Gama, Lisboa, Comissão Nacional para as Comemorações dos Descobrimentos Portugueses, 1998, p. 92.

${ }^{71}$ BA, 50-V-33, fls. 399-399v. 
Os matrimónios eram antecedidos pela celebração de capitulações nupciais mediante as quais era acordado dote da noiva e garantida a sua restituição em determinadas circunstâncias. Pelo seu casamento com D. Beatriz, por exemplo, foram prometidos a D. Jorge $11.000 \$ 000$ reais pagos durante três anos e em vários géneros, de bens móveis a dinheiro cobrado dos bens da Coroa dos sogros. $\mathrm{O}$ dote de D. Juliana foi definido em termos semelhantes, sendo estabelecido o pagamento de $20.000 \$ 000$ reais ao longo de seis anos e discriminados os senhorios da Casa de Vila Real onde se cobraria o dinheiro ${ }^{72}$. O contrato de casamento de D. Jorge II com D. Madalena acordava que os 32.000\$000 réis prometidos seriam entregues sob a forma de mercês régias, joias e outros bens móveis, padrões de juro e dinheiro ${ }^{73}$, enquanto o segundo casamento do duque de Torres Novas garantia somente a legítima da duquesa, certas joias e as mercês régias habitualmente recebidas pelas filhas dos Grandes de Espanha ${ }^{74}$.

As contrapartidas apresentadas pelos noivos corresponderam a um terço do dote. Para esse efeito, hipotecaram as rendas, bens da Coroa e jurisdições dos seus senhorios. Em 1500 e 1568, foram penhorados os rendimentos da vila de Torres Novas, enquanto em 1547 as arras eram garantidas com as rendas de Aveiro e de Montemor-o-Velho. A terça parte do dote de D. Ana Maria assegurou-se hipotecando todos os estados da Casa de Aveiro, à qual se somou a promessa de o duque de Torres Novas despender mensalmente $200 \$ 000$ réis para os gastos da sua câmara e de, em caso de viuvez, a duquesa também poder optar por assentar residência num senhorio à sua escolha. Quando os primeiros duques de Aveiro casaram, foi também estabelecida a instituição de um morgado com o valor do dote e o seu progressivo acrescentamento.

Em jeito de conclusão, importa recordar a elevada média de nascimentos ocorridos na Casa de Aveiro durante os séculos XVI e XVII e o relativo equilíbrio na geração de homens e de mulheres. A sua distribuição no decurso deste período ocorreu de forma desigual em virtude da elevada fertilidade de dois casamentos, cuja durabilidade constituiu a principal causa do elevado número de filhos e filhas gerados, assim como da esterilidade de um número igual de matrimónios. Estes últimos dois casos, contudo, não originaram grandes consequências a nível sucessório. O duque de Torres Novas casou uma segunda vez e o seu filho D. Raimundo contraiu matrimónio somente depois de abandonar Portugal. Não obstante a administração régia sob a qual a Casa de Aveiro foi

\footnotetext{
${ }^{72}$ António Caetano de Sousa, Provas..., VI, cit., p. 45-54.

${ }^{73}$ Archivo Historico Nacional (Toledo), Sección Nobleza, Osuna, C. 9, D. 26-27.

${ }^{74}$ António Caetano de Sousa, Provas..., VI, cit., p. 79-89.
} 
colocada após a sua fuga, a ampla descendência deixada pelos seus avós e pais acabou por garantir a sua sucessão ao fim de uma década.

Houve ainda um certo equilíbrio entre os descendentes que adotaram o celibato e os que casaram, muito embora o estado tomado por cada filho e cada filha tenha dependido de diversos fatores. As mulheres foram maioritariamente encaminhadas para casas religiosas e as que casaram constituíram exceções ocorridas sem nenhuma relação com o seu posicionamento na ordem de nascimento e em contextos bastante específicos. Quando não contrariaram a disciplina familiar a que estavam sujeitas, os matrimónios das filhas celebraram-se na ausência de descendentes do sexo masculino ou, porventura, consumando alianças com outras casas senhoriais. Os casamentos dos homens perfizeram a clara maioria tanto da população masculina como do conjunto de filhos que contraíram matrimónio e corresponderam sempre aos primeiros filhos na ordem de nascimento, independentemente do número de filhos de cada casamento. $\mathrm{O}$ maior investimento no matrimónio de filhos e a prevalência do ingresso das filhas em casas religiosas parecem, pois, corresponderem a uma estratégia familiar que pretendia simultaneamente assegurar a sucessão na Casa de Aveiro e preservar os seus recursos. Neste sentido, a análise dos percursos individuais das filhas e dos filhos da Casa de Aveiro, nascidos nos séculos XVI e XVII, constitui um contributo relevante para o conhecimento das estratégias familiares da aristocracia portuguesa da Época Moderna. 